\title{
EL PUNT DE RUPTURA ENTRE TOMÀS D'AQUINO I VICENT FERRER, O LA POSSIBILITAT DE CONÈIXER ELS TEMPS FINALS*
}

\author{
THE BREAKPOINT BETWEEN THOMAS AQUINAS AND \\ VINCENT FERRER, OR THE POSSIBILITY OF KNOWING \\ THE END TIMES
}

\author{
JAUME MEnSA I VALLS \\ Universitat Autònoma de Barcelona \\ http://orcid.org/0000-0002-3750-1226
}

\begin{abstract}
Resum: Aquest article compara les tesis de Tomàs d'Aquino i Vicent Ferrer sobre la possibilitat de conèixer els temps finals per revelació bíblica. Durant temps Vicent Ferrer seguí les idees del Doctor Comú, però entre els anys 1408 i 1412, se n'apartà. L'anàlisi de dos sermons i una lletra vicentins escrits entre aquests anys permeten de constatar la seva evolució. Vicent Ferrer passa de la negativa categòrica (tomista) a afirmar la possibilitat, necessitat i conveniència de conèixer aquells temps finals. El punt de ruptura entre ambdós autors es produeix en la seva exegesi de Fets dels Apòstols I,7.
\end{abstract}

Paraules clau: apocalíptica; Tomàs d'Aquino; Vicent Ferrer; Anticrist; fi del món.
Abstract: This paper compares the theses of Thomas Aquinas and Vincent Ferrer concerning the possibility of knowing the end times as revealed in the Bible. For years Vincent Ferrer followed the ideas of the Common Doctor of the Church, but between 1408 and 1412 he changed his position. The analysis of two sermons and one letter written by Vincent Ferrer between the aforementioned years allows us to observe his evolution. Vincent Ferrer abandoned the categorical refusal of Thomism for an assertion of the possibility, necessity and desirability of knowing these end times. The breakpoint between both authors occurs in their exegesis of Acts I, 7.

Keywords: apocalypticism; Thomas Aquinas; Vincent Ferrer; Antichrist; the end of the world.

\footnotetext{
* Projecte de recerca: "Corpus Digital d'Arnau de Vilanova: Filosofia i ciència a la Corona d'Aragó (segles XIII-XIV)”, MEC, FFI2014-53050-C5-2-P.
} 


\section{SUMARI}

1. Introducció.- 2. Tomàs d'Aquino i la negativa absoluta a conèixer els darrers temps.- 3. Vicent Ferrer i la possibilitat de conèixer els darrers temps.- 3.1. El sermó de Montpeller del dia 5 de desembre de 1408.- 3.2. El sermó de Toledo del dia 8 de juliol de 1411.- 3.3. L'Epistola de tempore Antichristi et fine mundi (Alcanyís, 27 de juliol de 1412).- 4. Conclusió.- 5. Bibliografia citada.

\section{INTRODUCCIÓ}

El dominic Vicent Ferrer es va formar filosòficament i teològicament amb l'estudi de les obres del gran teòleg i pensador del seu Orde, Tomàs d'Aquino'. Sabem que va escriure comentaris personals a la Summa Theologiae $^{2}$. Les reportationes dels sermons predicats per Vicent Ferrer sobre Tomàs d'Aquino mostren la consideració i l'admiració que sentia per ell ${ }^{3}$. En general, els diversos aspectes del pensament vicentí segueixen fidelment les línies doctrinals del Doctor Comú o en són actualitzacions i adaptacions a les noves problemàtiques de l'època ${ }^{4}$. Filosòficament, la seva teoria dels universals (ontologia) o de la suppositio (lògica) representen una reformulació reeixida de les tesis tomistes davant les dificultats plantejades pel nominalisme ${ }^{5}$. La influència del pensament de Tomàs d'Aquino també la podem resseguir en els diversos elements de filosofia política de l'obra vicentina ${ }^{6}$. Especialistes de l'obra de Vicent Ferrer han destacat que l'esmentada Summa Theologiae és el veritable eix dels diversos temes de la seva teologia: trinitària, cristològica, eclesiològica, espiritual, moral ${ }^{7}$.

\footnotetext{
${ }^{1}$ Per a la bibliografia de Vicent Ferrer, vegeu Forcada, Garganta 1956; Alemany 1995; Robles 1998.

${ }^{2} \mathrm{Cf}$. Madalena 1719.

${ }^{3}$ Cf. els sermons Hic magnus vocabitur in regno caelorum i Venit in me Spiritus Sapientiae. Dins l'indispensable article de Perarnau 1999, p. 619, núm. 395, p. 790, núm. 871; el lector interessat trobarà informació sobre els manuscrits i les edicions. La divisió temàtica (indicada per J. Perarnau) del primer sermó és la següent: "beatus Thomas vocabitur magnus [...] propter tres rationes: por vida virtuosa; por sciencia illuminosa; por muerte preciosa".

${ }^{4}$ El Capítol general de 1346 va establir l'obligació estricta dels Frares Predicadors de seguir la doctrina de Tomàs d'Aquino. Sobre aquest aspecte i la presència del tomisme a València, vegeu Gallego 1974.

${ }^{5}$ Ferrer 1977, 2010. A més de les respectives introduccions a les edicions citades d'aquestes obres, vegeu Beuchot 1995; García 1994.

${ }^{6}$ Beuchot 1995, p. 113, afirma: "Utilizará principios de la escuela aristotélico-tomista para dilucidar cuestiones tan concretas y arduas como el cisma de Aviñón, el conciliarismo, la guerra de los cien años, la tolerancia religiosa con moros y judíos, etc.".

${ }^{7}$ Vegeu, per exemple, Esponera 2007, p. 230; Fuster 2004, p. 280. Aquest darrer autor afirma, de Vicent Ferrer, que "La columna vertebral de su pensamiento es la Suma teológica de
} 
Ara bé, Vicent Ferrer, si més no durant els darrers anys de la seva vida, s'aparta del pensament de Tomàs d'Aquino en un aspecte central per a tots dos autors, el de les previsions escatològiques. Si el Doctor Comú va reaccionar contra aquells mestres seculars (Guillem de Sant Amor i seguidors) que pensaven que alguns fets de l'època (per exemple, el capteniment dels frares mendicants) ${ }^{8}$ auguraven la immediata vinguda de l'Anticrist i la fi dels temps, Vicent Ferrer es presentava com el praedicator finis mundi, l'àngel de l'Apocalipsi i el Legatus a latere Christi que anunciava la proximitat dels darrers dies ${ }^{9}$. Alguns autors també assenyalen coincidències entre Tomàs d'Aquino i Vicent Ferrer en aquest tema. Així, per exemple, el reconegut estudiós Sebastián Fuster arriba a la conclusió següent ${ }^{10}$ : Tengo para mí que san Vicente Ferrer discurre por una vía claramente tomista. Òbviament, en la mesura que la temàtica de l'Anticrist ja apareix en els llibres que formen el Nou Testament, els pensadors cristians comparteixen unes posicions mínimament comunes. Ara bé, més enllà d'aquestes posicions comunes, que certament també són observables entre els dos autors que són objecte del nostre estudi, les diferències entre ells (en el tema estudiat ara per nosaltres) acaben essent radicals, raó per la qual, tal com intentarem mostrar en aquestes pàgines, l'afirmació de $\mathrm{S}$. Fuster i dels estudiosos que pensen com ell, considerada globalment i absoluta, no fa justícia a la realitat. En aquestes pàgines ens proposem d'analitzar el que creiem que és el punt doctrinal de ruptura entre ambdós pensadors, és a dir, la diversa interpretació de la frase de Fets dels Apòstols I,7 que l'evangelista Lluc posa en boca de Jesucrist com a resposta a la pregunta dels Apòstols sobre el temps escatològic i la restitució del Regne d'Israel: Non est vestrum nosse tempora vel momenta, quae Pater posuit in sua potestate.

Tomás de Aquino" i que és "Un teólogo identificado con Tomás de Aquino". Vegeu Garganta 1908, p. 158: "Vicente Ferrer tenía un esquema teológico bien asimilado, de corte y contenido tomista; dominaba la Summa de santo Tomás, incluso en su parte moral y hace uso de ella normalmente". En aquest darrer estudi el lector interessat pot trobar una presentació general de la predicació vicentina: tradició hagiogràfica, estat de la qüestió, etapes, fonts, sentit i caràcter de la predicació, tècnica. L'autor insisteix en el fet que "San Vicente, repetimos, es predicador escatológico, más que apocalíptico", ibidem, p. 151.

${ }^{8}$ Dufeil 1972; Geltner 2012, pp. 159-182; Lambertini 2002.

${ }^{9}$ Fages 1903, p. 327.

${ }^{10}$ Fuster 2004, p. 107. Sobre el llibre de S. Fuster, vegeu l'extensa i molt suggerent recensió de Perarnau 2007, pp. 816-820. 


\section{TOMÀS D'AQUINO I LA NEGATIVA ABSOLUTA A CONÈIXER ELS DARRERS TEMPS}

En el context de la polèmica entre els mestres seculars i els frares mendicants, Tomàs d'Aquino es planteja diverses vegades si és possible conèixer els temps de la vinguda de l'Anticrist. Efectivament, ja en el Liber contra impugnantes Dei cultum et religionem, de l'any 1256, dedica la qüestió 24 i, en part i més indirectament, la 25 a aquest tema ${ }^{11}$. Entre aquest any i el 1271 , Tomàs d'Aquino farà diverses aportacions més o menys puntuals, en les obres següents: Scriptum super Sententiis, IV, d. $43^{12}$; Quaestiones disputatae de veritate, q. 8. a. 12 i q. 12 , a. $8^{13}$; i Quaestiones disputatae de potentia, q. 5 , a. $6^{14}$.

És possible, doncs, conèixer els temps de l'Anticrist segons Tomàs d'Aquino ${ }^{15}$ ? Em sembla que podem sintetitzar la seva posició de la manera següent: La humanitat pot tenir notícia del futur per coneixement natural o per revelació. Allò relatiu a la fi del món i a la vinguda de l'Anticrist (en realitat són esdeveniments que es produiran amb poc temps de diferència entre l'un $\mathrm{i}$ l'altre) no poden ser coneguts per coneixement natural, perquè l'única causa del moviment del cel i del seu cessament és la voluntat divina ${ }^{16}$. Descartat, doncs, un coneixement natural de la fi del món i de la vinguda de l'Anticrist, Tomàs d'Aquino es pregunta si aquest coneixement és possible per revelació. Per revelació tampoc és possible ut omnes semper sint soliciti et praeparati ad Christo occurrendum i per aquesta raó Jesucrist va respondre als Apòstols (Fets dels Apòstols I, 7) ${ }^{17}$ : non est vestrum nosse tempora vel momenta, quae Pater posuit

${ }^{11}$ Thomas de Aquino 1970a, pp. 159-162, 162-165.

${ }^{12}$ Thomas de Aquino 1858, p. 1.064b.

${ }^{13}$ Thomas de Aquino 1970b, pp. 257-260, 393-394.

${ }^{14}$ Thomas de Aquino 1949, pp. 145-147.

En general sobre l'escatologia de Tomàs d'Aquino i en particular sobre la possibilitat de conèixer els temps de l'Anticrist, vegeu Moya 2000; Velde 2002; Elizande 2004; Fiorentino 2007; Bianchi 1998; Dabrowski 2011; Lamb 2007.

${ }^{15}$ He dedicat bona part d'un estudi a reconstruir la posició de Tomàs d'Aquino sobre la possibilitat de conèixer els temps de l'Anticrist, Mensa 2014. A continuació en sintetitzem les tesis principals.

${ }^{16}$ Thomas de Aquino 1858, vol. IV, d. 43, q. 1, a. 3, qc. 2, co, p. 1.064b: "Determinatus numerus futuri temporis sciri non potest nisi vel per revelationem vel per naturalem rationem [...] Ex motu autem caeli non potest cognosci finis eius; quia cum sit circularis, ex hoc ipso habet quod secundum naturam suam possit in perpetuum durare". $C f$. també Thomas de Aquino 1949 , p. 146.

${ }^{17}$ Thomas de Aquino, 1858, IV, d. 43, q. 1, a. 3, qc. 2, co, p. 1.064b: "Similiter nec per revelationem haberi potest, ideo, ut omnes semper sint soliciti et praeparati ad Christo occurrendum; et propet hoc etiam Apostolis de hoc quaerentibus respondit Fets dels Apòstols I,7: «non est vestrum nosse tempora vel momenta, quae Pater posuit in sua potestate» (...) Quod enim Apostolis quaerentibus noluit indicare, nec aliis revelabit. Unde illi omnes qui tempus praedictum 
in sua potestate. I si no va voler revelar els darrers temps als Apòstols, encara menys els revelarà a la resta de la humanitat. És més, tal com diu Mateu XXIV, 36: de die illa et hora nemo scit, neque angeli caelorum, ni tan sols els àngels tenen coneixement d'aquells temps (l'expressió dia $i$ hora significa temps, en general). I, tenint en compte que qualsevol revelació de Déu a les persones es fa per mitjà dels àngels, afirma Tomàs d'Aquino, si aquests no en saben res, és impossible que les persones en puguin tenir notícia per revelació ${ }^{18}$. Per a les persones, en consequiència, tempus determinatum finis mundi omnino nescitur ${ }^{19}$. La resposta de Jesús a la pregunta dels Apòstols, de Fets dels Apòstols I,7, és per a Tomàs d'Aquino ben clara: la negativa de conèixer els darrers temps és absoluta tant per als Apòstols com, amb més motiu, per a la resta de la humanitat.

Tomàs d'Aquino està convençut que la seva interpretació de Fets dels Apòstols I,7 -i en general les seves tesis sobre el coneixement dels darrers temps- és la mateixa que Agustí d'Hipona ja va sostenir en la seva època ${ }^{20}$. Alguns dels signes que els adversaris de Tomàs d'Aquino creien que anticipaven i permetien de preveure la imminent vinguda de l'Anticrist, ja es van produir fins i tot abans dels temps d'Agustí d'Hipona i, això no obstant, la vinguda de l'Anticrist i la fi del món no va $\operatorname{arribar}^{21}$.

numerare voluerunt, hactenus falsiloqui sunt inventi"; o Thomas de Aquino 1949, q. 5, a. 6 , s.c. 2, p. 146: "Praeterea, si aliquid deberet aliquibus hominibus revelari, praecipue revelatum fuisset quaerentibus Apostolis, qui doctores totius mundi instituebantur. Eis autem de finali adventu Domini quaerentibus responsum est", Apòstols I,7: “"Non est vestrum nosse tempora vel momenta, quae Pater posuit in sua potestate». Ergo multo minus est aliis revelatum".

${ }^{18}$ Thomas de Aquino, 1858, IV, d. 43, q. 1, a. 3, qc. 2, s. c. 1, p. 1.063a: "Illud quod est ignoratum ab angelis, est etiam hominibus multo magis occultum; quia ea ad quae homines naturali ratione pertingere possunt, multo limpidius et certius angeli naturali cognitione cognoscunt; similiter etiam revelationes hominibus non fiunt nisi mediantibus angelis, ut patet per Dionysium, 4 cap. Cael. Hier. Sed angeli nesciunt tempus determinate, ut patet Matth. XXIV, 36: «de die illa et hora nemo scit, neque angeli caelorum». Ergo tempus illud est hominibus occultum". $C f$. també l'article 12 , "utrum angeli cognoscant futura", de la q. 8 ; i l'article 8 , "utrum omnis revelatio prophetica fiat angelo mediante", de la q. 12, de las Quaestiones disputatae de veritate, Thomas de Aquino $1970 \mathrm{~b}$.

${ }^{19}$ Thomas de Aquino 1949, q. 5, p. 146.

${ }^{20}$ Thomas de Aquino 1970a, c. 24, pp. 159-160, 1. 39-62: "Dominus enim Act. I,7, quaerentibus discipulis de hoc ipso, respondit «Non est vestrum nosse tempora vel momenta quae pater posuit in sua potestate»; ex quo argumentatur Augustinus in Epistola ad Hesychium, quod si non est eorum nosse, multo minus aliorum. Et Mateu XXIV, 36 : «De die autem illa et hora nemo scit, neque angeli caelorum», et hoc idem habetur Marc XIII, 32: «Non moveamini a vestro sensu quasi instet dies domini. Et Augustinus Ad Hesychium loquens Dixisti: Evangelium dicit: De die et hora nemo scit; ego autem, inquit, pro possibilitate intellectus mei dico, neque mensem neque annum adventus ipsius sciri posse: ita enim hoc videtur sonare tamquam non possit sciri quo anno venturus sit, sed posset sciri qua hebdomade annorum, vel qua decade»; et infra «Quod si ne hoc quidem comprehendi potest, quaero utrum sic saltem possit diffiniri tempus adventus eius ut eum venturum esse dicamus infra istos, verbi gratia vel quinquaginta vel centum annos vel quotlibet seu maioris numeri seu minoris annorum»; et infra «Si autem nec hoc te comprehendisse praesumis, hoc sentis quod ego»".

${ }^{21}$ Ibidem, pp. 160-162, 1. 98-305. 
Tomàs d'Aquino desenvolupa, com hem dit en començar aquest apartat, la interpretació de Fets dels Apòstols I, 7 i en general les seves tesis contra la possibilitat de conèixer els darrers temps en el context de la polèmica entre el clergat secular i els ordes mendicants. La seva posició, però, no té res de circumstancial o accidental. Tal com han mostrat el estudis de T. Gregory ${ }^{22}$, el que podem anomenar atemporalització de l'escatologia cristiana pròpia de Tomàs d'Aquino (una concreció de la qual és el tema que estem estudiant) és una conseqüència lògica d'haver assumit bona part dels plantejaments de la filosofia aristotèlica i d'haver estructurat la teologia segons el model de la ciència aristotèlica. Bo i relegant a un lloc secundari, o fins i tot abandonant, el pla històric constitutiu de la teologia tradicional, és a dir, de la teologia entesa com a lectio historiae -i de comprensió, doncs, d'un ordo temporum-, i per tal d'assumir l'estructura sil-logística i intemporal de la ciència, la teologia de Tomàs d'Aquino adoptava un modus argumentativus aliè a la tensió escatològica inherent a la lectio historiae ${ }^{23}$.

\section{VICENT FERRER I LA POSSIBILITAT DE CONÈIXER ELS DARRERS TEMPS}

Vicent Ferrer interpreta o reinterpreta el text de Fets dels Apòstols I, 7-8 tres vegades successives. La primera d'aquestes tres vegades la trobem en el sermó que té com a tema Reminiscamini quia ego dixi vobis (Joan XVI, 4) i fou predicat el dimecres dia 5 de desembre de 1408 a Montpeller ${ }^{24}$; la segona, forma part del sermó del mateix tema predicat a Toledo el dia 8 de juliol de 141125; i la tercera, de l'Epistola fratris Vincentii de tempore Antichristi et fine

${ }^{22}$ Gregory 1962, 1965.

${ }^{23}$ Ibidem, pp. 89-90. Afirma també Gregory 1962, p. 267: "il passaggio dalla teologia come lectio historiae alla teologia come scienza, dalla series narrationis alla scientia consequentiarum, comporta l'abbandono proprio della dimensione temporale ed ascatologica della teologia: la rivelazione viene sussunta negli schemi intemporali della teoria aristotelica della scienza".

${ }^{24}$ La reportatio d'aquest sermó (IV. Sermon donné le mercredi 5 décembre 1408 à Montpellier) s'ha conservat en el còdex de Lausana, BCU, G 756, i ha estat editat per Morenzoni 2004, pp. 259-267.

${ }^{25}$ Aquest sermó (26. Sermón III ${ }^{o}$ del Antechristo) ha estat editat per Cátedra 1994, pp. 561473, de la reportatio conservada a Madrid, Real Academia de la Historia, ms. 294, ff. 154r-160r. Aquest sermó ja havia estat publicat anteriorment per Carbonero 1873. D'aquest mateix sermó n'hi ha dues reportationes, molt més breus, conservades en el còdex de València, Col·legi del Corpus Christi, f. 70r-v, i en la Relaçión a Fernando de Antequera, editada també per Cátedra 1994, pp. 663-672, concretament pp. 670-672, línies 236-305, del còdex d'Oviedo, Biblioteca Universitaria, ms. 444, ff. 125r-127r. Per la breu reportatio del manuscrit del Col-legi del Patriarca (Corpus Christi), f. 4r, sabem que Vicent Ferrer va predicar també un sermó sobre el mateix tema el dia 18 de febrer de 1411, segurament a Múrcia. $C f$. Perarnau 1999, p. 747, núms. 738-739. 
mundi adreçada a Benet XIII i datada a Alcanyís, el dia 27 de juliol de $1412^{26}$. Tenint en compte que la base d'aquesta lletra és l'esmentat sermó predicat a Toledo, els tres textos que analitzarem en realitat són variacions del mateix tema i segueixen una estructura comuna, la qual cosa ens permetrà de comparar més fàcilment l'evolució del pensament vicentí sobre la possibilitat de conèixer la fi dels temps entre aquestes dates.

Entre la data del primer text analitzat (5 de desembre de 1408) i la data del darrer (27 de juliol de 1412) només han passat tres anys i mig, però és un temps molt significatiu. Efectivament, els estudiosos (R. Rusconi, C. Delcorno) solen distingir dos períodes en la predicació itinerant de fra Vicent: la primera comença l'any 1399, quan com a conseqüència d'una malaltia i d'una visió abandona Avinyó i enceta una etapa radicalment nova en la seva vida, de predicació arreu dels països d'Europa. Aquest primer període acaba aproximadament entre els anys 1408-1409. És un període marcat especialment per la penitència i la catequesi moral. El segon període, que va de l'any 1408-1409 al 1419, any de la mort de mestre Vicent, és molt més escatològic. Entre ambdós períodes hi ha un gir molt $\mathrm{clar}^{27}$. Els tres fragments que tot seguit analitzarem foren escrits, doncs, en uns moments de canvi, de transició d'un període cap a l'altre.

\subsection{El sermó de Montpeller del dia 5 de desembre de 1408}

Carlo Delcorno ha destacat la importància d'aquest sermó, precisament perquè és el testimoni d'un canvi en la predicació de Vicent Ferrer. Aquest canvi consisteix en l'ús central i insistent del motiu de les tres llan$\operatorname{ces}^{28}$. Ja fa cent anys, diu Vicent Ferrer, que, segons una revelació feta a sant Francesc i sant Domènec, el món s'havia d'acabar i que Crist havia d'enviar les “tres llances", és a dir, la persecució de l'Anticrist, la deflagració del món i el judici final, però, per concedir una darrera oportunitat als pecadors, a petició de la verge Maria, n'ajornà un temps l'execució. I aquest temps afegit, creu Ferrer, s'ha acabat.

${ }^{26}$ D'aquesta epístola n'hi ha diverses transcripcions. Nosaltres utilitzarem la de Fages 1905, pp. 213-224. Actualment, Paul-Bernard Hodel en prepara l'edició crítica. Vegeu, també, l'estudi següent Hodel 2005.

${ }^{27}$ Cf. Rusconi 1979, pp. 220-223. A la p. 223, llegim: "Nel secondo decennio della sua predicazione itinerante, che va dal 1409 al 1419 , vi è indubbiamente una svolta nell'atteggiamento di Vicent Ferrer nei confronti dell'Anticristo e delle attese escatologiche in generale"; Delcorno 2006, pp. 7-38, concretament pp. 10-12. Aquest darrer estudi també ha estat publicat dins Delcorno 2009, pp. 263-289. Delcorno 2006, p. 11, avança un any la data del canvi, és a dir, es produeix "tra il novembre e il dicembre del 1408".

${ }^{28}$ Ibidem, p. 11. 
El sumari inicial d'aquest sermó ja anuncia tres conclusions. La primera és que adventus Antichristi non potest sciri determinative quantum ad annum, mensem vel septimanam, diem et horam ${ }^{29}$. La segona, que l'Anticrist ja havia d'haver vingut cent vuitanta anys enrere. I la tercera, que ha de venir immediatament ${ }^{30}$. La primera conclusió és argumentada de la manera següent: conèixer el temps de l'Anticrist significa conèixer la fi del món, perquè ambdós fets es produiran amb poc temps de diferència. Efectivament, l'Anticrist regnarà tres anys i mig (Daniel XII, 7; Apocalipsi XII, 14) i un cop sigui vençut i notificada la seva mort el món durarà quaranta dies i s'acabarà. Ja Joan Baptista predicava l'adveniment de l'Anticrist, però quan els Apòstols van preguntar a Jesús (Mateu XXIV, 3) pel temps de la seva vinguda ell els va dir: De die autem illa et hora nemo scit, neque angeli caelorum, nisi solus Pater (Mateu XXIV, 36). Literalment, doncs, les paraules de Jesús neguen aquest coneixement als profetes, als Apòstols, als màrtirs, als sants del cel. I, doncs, non mirum si nos nescimus cum ipsi nesciant ${ }^{31}$. Quan els Apòstols i la verge Maria, abans de l'ascensió li varen tornar a preguntar per aquests temps (Fets dels Apòstols I, 6), Jesucrist els va dir: Non est vestrum nosse tempora vel momenta, quae Pater posuit in sua potestate (Fets dels Apòstols I, 7), la qual cosa significa non spectat ad vos scire talia, scilicet per numera; maiorem autem graciam faciam vobis, quia mittam Spiritum Sanctum qui confirmabit vos ut possitis resistere ${ }^{32}$. Aquesta interpretació de Vicent Ferrer és la mateixa que la de Tomàs d'Aquino. Hi ha, però, en el mateix sermó una nova referència al fragment de Fets dels Apòstols I, 7. Quan mestre Vicent argumenta la tercera conclusió aporta diversos testimonis que confirmen que l'Anticrist ja era nat. Entre aquests testimonis hi ha el següent ${ }^{33}$ : un ermità li va explicar que dos altres ermitans, molt devots $i$

\footnotetext{
${ }^{29}$ Vegeu Morenzoni 2004, p. 259, línies 4-7. Aquesta primera conclusió és desenvolupada en pp. 259-262, línies 10-123.

${ }^{30}$ Ibidem, p. 259, línies 6-7, 7-9, respectivament. Són argumentades en pp. 262-264, línies 124-226; pp. 264-267, línies 227-310.

${ }^{31}$ Ibidem, p. 260, línia 39. El fragment sencer, p. 260, línies 36-47, fa: "Verba ista [Mateu XXIV, 36] habentur ad litteram ubi supra, quia neque prophete, neque apostoli, neque martires, nec aliquis sanctus paradisi, ut probantur Actuum primo capitulo, istum adventum scit, nisi solus Pater. Et ideo non mirum si nos nescimus cum ipsi nesciant. Item sancti apostoli et omnis alii sancti cum Virgine Maria quando viderunt quod ipse volebat adscendere in celum, iterum ipsum interrogaverunt, dicentes: «Domine, quando erit finis mundi, quando restitues regnun Israel?» Hoc est, si modo. Et ipse respondit eis: «non est vestrum nosse tempora vel momenta que Pater posuit in sua potestate», Actuum primo capitulo. Hoc est dicere: non spectat ad vos scire talia, scilicet per numera; maiorem autem graciam faciam vobis, quia mittam Spiritum Sanctum qui confirmabit vos ut possitis resistere. Et ita patet quomodo est probata ista conclusio prima quod nemo scit determinate adventum antichristi".

${ }^{32}$ Ibidem, p. 260, línies 44-47.

${ }^{33}$ Ibidem, p. 266, línies 286-295: "Item dico vobis quod in loco de Monserat quidam heremita dixit michi quod heremite, credo quod duo, morabantur in tali monte, et hoc in Lumbardia de quo non recordor, videlicet de nomine montis. Et illuc fuit eis revelatum quod antichristus era
} 
dignes de fe, tingueren una revelació segons la qual l'Anticrist ja havia nascut. Mestre Vicent va replicar que tal revelació era impossible perquè Jesús havia pronunciat les paraules Non est vestrum nosse tempora vel momenta, quae Pater posuit in sua potestate (Fets dels Apòstols I, 7). L'ermità que explicava el fet a Vicent Ferrer, i havia fet mans i mànigues per poder parlar amb ell, li va dir que aquesta negativa era vàlida per als temps dels Apòstols, però que ara en canvi convenia de conèixer aquells temps. El text, efectivament, no ens diu si Vicent Ferrer estigué d'acord o no amb la interpretació de l'ermità, però, en la mesura que inclou la revelació per ell explicada entre els testimonis que certificarien la tercera conclusió, pensem que es va deixar convèncer per les paraules de l'ermità. Si Vicent Ferrer s'hagués mantingut absolutament ferm en la seva actitud inicial, segons la qual non poterat esse, no hauria fet cas d'aquella revelació ni l'hauria inclosa en el seu sermó ${ }^{34}$.

\subsection{El sermó de Toledo del dia 8 de juliol de 1411}

En la narració de l'explicació que li féu l'ermità sobre la revelació del naixement de l'Anticrist feta a dos altres ermitans elimina les referències (la seva objecció i la resposta de l'ermità) a les paraules de Jesús de Fets dels Apòstols I, 7:

La terçera, buena gente, es que ocho años son passados que yo predicava por Lombardía en una villa que llaman Channas. E en aquella villa non avemos monesterio, sinon los frayres de sant Françisco, e yo posava con ellos. E estando aý, vino a mí un hermitaño que non vestía otra cosa sinon cáñamo. E, segúnd a mí paresçía, era omne de buena vida. E díxome: -Padre, yo vengo a vos, que me dixieron que predicávades la fin del mundo e del avenimiento del Antichristo-. E yo dixe que ssí. E él díxome: - ¿Sabedes quándo es?- E yo dixe que non. E díxome: -Pues yo vengo a vos a dezírvoslo por mandado de dos honbres santos que les fue revelado, que están en esta tierra-. E estos dos religiosos que lo han visto, que es nasçido el Antichristo. E díxele: -Amigo, yo lo predicaré que me lo dixistes vós, mas non lo porné por conclusión-. E dígovoslo rrezando, mas yo lo creo en mi coraçón ${ }^{35}$.

natus. Et ipsi heremite erant fide digni et multum devoti. Et ego replicavi ei dicendo quod non poterat esse, et allegavi testimonium Biblie: «non est vobis noxe», et cet. Et heremita respondit quod illud habebat verum tempore apostolorum, sed nunc erat expediens quod sciretur. Et ipse heremita per multa loca me investigaverat ut illa posset michi manifestare, attento quod audiverat dici quod ego predicabam adventum antichristi".

${ }^{34}$ Ibidem, p. 266, línia 290.

${ }^{35}$ Ibidem 1994, p. 571-572, línies 373-385. Malgrat alguna petita variació de circumstàncies, no hi pot haver cap mena de dubte que el fet històric explicat és el mateix. 
En canvi, Vicent Ferrer fa notar la distància preventiva respecte de la revelació reportada per l'ermità dient-li que la inclourà en els seus sermons no com una conclusió pròpia sinó com un fet que li han explicat.

En l'argumentació de la primera conclusió, assumeix com a pròpia la interpretació de Fets dels Apòstols I, 7 que en el sermó de Montpeller havia fet l'ermità: la negativa de Jesús anava dirigida als Apòstols i a tots aquells que no havien de viure en temps de l'Anticrist. En conseqüència, no els pertocava de conèixer aquells temps, però, en canvi, sí que pertoca a les persones que han de participar en la batalla contra l'Anticrist, és a dir, als contemporanis de mestre Vicent:

Pues, Señor, ¿a quién pertenesçe? Non pertenesçía de lo saber ellos, pues que non devían ser en la batalla. ¿E qué pertenesçe al rrey de Castilla nin a sus cavalleros saber la batalla que se faze en Ungría, pues que non tienen que estar en ella? Mas los que tienen que estar en ella es razón que lo sepan. Assý, a los apóstoles e disçípulos de Ihesú Christo non les calía saber la batalla del Antichristo nin de la fin del mundo, pues non devían ser en ella, mas cale saber a nosotros, mesquinos, que avemos de ser en la batalla, por que non vamos desanparados ${ }^{36}$.

Davant el retret que algú podria fer a aquesta interpretació, consistent a preguntar-se si soy yo [és a dir, fra Vicent] alunbrado más que los apóstoles nin santos, Vicent Ferrer afirma que això és així per nesçesidat i disposició de Déu ${ }^{37}$.

I per tal de fer compatible aquesta interpretació de Fets dels Apòstols I, 7 amb l'altre verset bíblic (Marc XIII, 32: De die autem illo vel hora nemo scit, neque angeli caelorum, neque Filius, nisi Pater) que li serveix per a argumentar la primera conclusió del sermó, mestre Vicent matisa: Él [el Fill] bien lo sabe, mas non para dezirlo [a los apóstoles], de la mateixa manera que, quan una persona pregunta a una altra persona per alguna cosa, i aquesta la sap però no la vol dir, diu que no ho sap ${ }^{38}$.

${ }^{36}$ Ibidem, p. 564, línies 100-107. En la Relaçión a Fernando de Antequera (Ibidem, p. 671, línies 253-256) l'exegesi de Fets dels Apòstols I, 7 és resumida així: "al tienpo de la abçensión los deçípulos preguntáron-le: «Si in tempora hic restias, etc.». Esto porque se non avían de açertar ellos en la batalla e la conquista de Antichristo, pues non avía de ser en su tiempo, por lo qual non era suyo nin avían mester de lo saber".

${ }^{37}$ El fragment sencer, ibidem, p. 564, línies 108-112, fa: "Mas dirá alguno: «-¿Qué? ¿Soy yo alunbrado más que los apóstoles nin santos, pues que ellos non lo sabían?-» Yo digo que non ay más ignorante a conparaçión de los santos e apóstoles que yo, mas esto es por nesçesidat: «Non est vestrum, etc.». Dize: «Esto non pertenesçe a vosotros», dezía Ihesú Christo, mas a nosotros, mesquinos".

${ }^{38}$ Ibidem, p. 563, línies 71-74, 79-80: “Aquí hay secreto. ¿Por qué dize que el Fijo de Dios non lo sabe? Ca Él bien lo sabe, mas non para dezirlo. Ca assí dize omne quando le pregunta 


\subsection{L'Epistola de tempore Antichristi et fine mundi (Alcanyís, 27 de juliol de 1412)}

Aquesta epístola segueix pràcticament el mateix esquema dels dos sermons anteriors. En comptes, però, de tres conclusions n'hi ha quatre: les tres dels sermons anteriors, que passen a ser ara respectivament la segona, la tercera i la quarta, i una d'aparentment nova, la primera, és a dir, quod tempus Antichristi et finis mundi in eodem coincidunt temporaliter ${ }^{39}$, però que en realitat no ho és, perquè en els dos sermons formava part de la primera conclusió (en el sermó de Montpeller) ${ }^{40}$, o d'una introducció general (en el de Toledo $)^{41}$.

La interpretació de Fets dels Apòstols I, 7 i la conclusió obtinguda és la mateixa que en el sermó de Toledo: Vicent Ferrer ha eliminat la referència al text bíblic en l'explicació de la revelació explicada per l'ermità ${ }^{42}$ i també ha fet seva l'exegesi de l'ermità:

Secundus textus habetur Actuum primo capite, ubi discipulis iterum querentibus de eodem, et dicentibus: Domine, si in tempore hoc restitues regnum Israel, respondit ipse Christus: Non est vestrum nosse tempora, vel momenta, etc., ubi ponderatum est hoc, quod dicitur Apostolis, non est vestrum, etc., ac si diceretur militibus, et doctoribus (alias comitibus) Hispanie: Non est vestrum scire tempus, el diem belli futuri in Tartaria, vel in Armenia, cum non habeatis ibi interesse; et tantum scire tempus illius belli in Tartaria, seu in Armenia, est Tartarorum, seu Armenorum etiam rusticorum, quia habent illic interesse, et se premunire. Sic non erat necessitas Apostolorum, nec Doctorum, aut sanctorum antiquorum, scire tempus Antichristi, seu finis mundi, quamvis essent illuminatissimi revelationibus divine sapientie; tamen expediens, et necessarium erat, ut homines post nativitatem Antichristi scirent illud tempus, ad se premuniendum, et preparandum,

otro alguna cosa; dize: -«Non lo ssé»-, aunque lo sepa, mas dize que non lo sabe para lo dezir a él (...) E por esto se entiende esta actoridad; que non lo sabe para lo dezir a los apóstoles".

${ }^{39}$ Fages 1905, p. 213.

${ }^{40}$ Morenzoni 2004, p. 259, línies 10-24.

${ }^{41}$ Cátedra 1994, pp. 561-562, línies 11-37.

${ }^{42}$ Fages 1905, p. 222: "Eadem conclusio ostenditur per aliam revelationem mihi relatam per quemdam virum devotum (ut mihi videtur) et sanctum. Nam cum ego predicarem in partibus Lombardie prima vice (modo jam sunt novem anni completi), venit ad me de Tuscia ille vir, missus (ut dicebat) a quibusdam sanctissimis eremitis in partibus Tuscie, in maxima vite austeritate per magna tempora degentibus, annuncians quod eisdem viris expresse revelationes divinitus facte fuerant, quod Antichristus jam erat natus, et quod istud debebat mundo denunciari, ut fideles ad tam terribile prelium se pararent, et quod propterea dicti sancti Eremite ipsum ad me mittebant, ut hoc mundo denunciarem; sic ergo patet ex hujusmodi revelationibus, si vere sunt, quod jam Antichristus est natus, et habet completos novem annos sue maledicte etatis, et per consequens predicta conclusio vera". 
quamvis peccatores ignorantes respectu Apostolorum, et aliorum Doctorum antiquorum Sanctorum ${ }^{43}$.

Com a novetat (respecte del sermó de Toledo), tot seguit, Vicent Ferrer fa notar que Déu, des del començament del món, sempre ha enviat nuncis per advertir els homes dels perills d'una tribulació imminent ${ }^{44}$.

\section{CONCLUSIÓ}

Segons Tomàs d'Aquino no és possible conèixer per revelació (ni per raó natural) els temps de l'Anticrist i de la fi del món: la resposta de Jesucrist als Apòstols (de Fets dels Apòstols I, 7) representa una negativa absoluta, sense excepcions, a aquest coneixement. Segurament Vicent Ferrer, ben format en la filosofia i la teologia de Tomàs d'Aquino, durant bona part de la seva vida va pensar exactament com el Doctor Comú. Una prova la tenim en el fet que en el sermó predicat a Montpeller del dia 5 de desembre de 1408 la primera tesi sigui, precisament, que adventus Antichristi non potest sciri determinative quantum ad annum, mensem vel septimanam, diem et horam ${ }^{45}$. L'acord entre ambdós autors és total. A partir d'aquest moment, però, el pensament de Vicent Ferrer sobre aquest tema evoluciona. Ho hem pogut constatar comparant dos sermons seus i l'Epistola de tempore Antichristi et fine mundi que tenen el mateix tema i segueixen la mateixa estructura i que foren predicats o escrits amb encara no quatre anys de diferència. Aquest escrits vicentins mostren clarament les passes de l'esmentada evolució: en el sermó predicat el dia 5 de desembre de 1408 la tesi de Vicent Ferrer, com acabem de veure, coincideix amb la de Tomàs de Aquino, però, ja cap al final del mateix sermó, aporta el testimoni d'un ermità segons el qual les paraules de Jesús eren plenament vàlides per als Apòstols i per a totes les persones que no havien de viure les tribulacions dels darrers temps, però que, en canvi, no afectaven aquelles persones que havien de participar en la batalla contra l'Anticrist. Si bé mestre Vicent, en un primer moment, va manifestar la seva estranyesa davant d'aquesta interpretació de l'ermità, i fins i tot hi va reaccionar en contra, poc després en el sermó predicat a Toledo el dia 8 de juliol de l'any 1411 i en l'Epistola de tempore Anticristi et fine mundi, del 27 de juliol de 1412, l'assu-

\footnotetext{
${ }^{43}$ Ibidem, p. 215.
}

${ }^{44}$ Ibidem 1905, p. 215. Per contra ara ha eliminat l'aclariment que havia fet a Toledo sobre el coneixement que tenia Jesucrist dels temps finals en el sentit que el posseïa, però no per a comunicar-lo als Apòstols.

${ }^{45}$ Vegeu Morenzoni 2004, p. 259, línies 4-7. 
mirà com a pròpia. Ara la formulació general, és a dir, la tesi que afirma que illud tempus fuit hominibus omnibus absconditum generaliter (amb el verb en passat), ja té una limitació ben clara: ante nativitatem Antichristi $i^{46}$; i, nascut doncs l'Anticrist, és convenient i necessari que tothom ho sàpiga. I aquest és el moment en el qual mestre Vicent predica o escriu els textos analitzats en aquest article (Antichristus jam erat natus) ${ }^{47}$. Aquesta nova interpretació vicentina de Fets dels Apòstols I, 7, em sembla, està en perfecta consonància amb la seva predicació dels darrers anys (almenys fins a l'any 1417) i a la vegada li serveix de fonament bíblic i teològic. Em pregunto, però, si Vicent Ferrer no s'ha apartat tant de l'exegesi de Tomàs d'Aquino (assumida com a pròpia fins l'any 1408) de Fets dels Apòstols I,7 i de la conclusió general que n'extreu, que les paraules que Tomàs d'Aquino va pronunciar contra Guillem de Sant Amor i els seus seguidors, no es podrien aplicar ara al sant valencià.

La periodització dels anys de predicació de Vicent Ferrer en dues etapes que alguns estudiosos (Rusconi, Delcorno) han proposat troben una confirmació més en aquestes pàgines nostres. A més, creiem, permeten de concretar i constatar els passos d'aquest canvi. Segurament, C. Delcorno té tota la raó del món quan afirma que un deciso mutamento si osserva già nella predicacione tenuta a Montpellier tra il novembre e il dicembre del 1408, com ho demostra el fet que ja hi ha pienamente trattato il motivo delle "tre Lance" 48 . És un canvi, però, en tot cas que Vicent Ferrer anirà desenvolupament progressivament en els propers mesos o fins i tot anys (tres i mig). En el mateix sermó de Montpeller, i malgrat la novetat d'alguns elements, pel que fa a la interpretació de Fets dels Apòstols I, 7, Vicent Ferrer encara es manté fidel a la exegesi tomista. La ruptura pròpiament dita entre l'exegesi tomista de Fets dels Apòstols I, 7 i Vicent Ferrer la trobem perfectament documentada en els fragments analitzats dels anys 1411 i 1412. Potser el pas del primer període de predicació, de signe més penitencial i moralitzant que escatològic, al segon període, més escatològic (o, més pròpiament, apocalíptic) que moralitzant i penitencial no es realitza tot d'una, d'un dia per l'altre, sinó que és un procés que implica un cert temps.

Més enllà de l'influx tomista, segurament altres corrents espirituals, amb un destacat component profètic i apocalíptic ${ }^{49}$, operen en el pensament

${ }^{46}$ Fages 1905, p. 215.

${ }^{47}$ Ibidem, p. 222.

${ }^{48}$ Delcorno 2006, p. 11.

${ }^{49}$ De vegades alguns estudiosos (p. ex., Garganta 1908, p. 151; Fuster 2004) insisteixen en la idea que la predicació de Vicent Ferrer no és pròpiament apocalíptica, ans més aviat escatològica. No crec que el qualificatiu "escatològic" sigui més apropiat que "apocalíptic" per a descriure els tres fragments estudiats en aquestes nostres pàgines: són sense cap mena de dubte sermons apocalíptics. 
de mestre Vicent dels darrers anys de la seva vida, o almenys fins al començament del concili de Constança o l'elecció de Martí V (1417) ${ }^{50}$. I si, com hem vist, les tesis (anti) apocalíptiques de Tomàs d'Aquino s'empeltaven (fins a l'any 1408) en el mateix tronc del seu pensament, ens podem preguntar ara fins a quin punt aquest canvi de Vicent Ferrer en la interpretació de Fets dels Apòstols I, 7 no afecta altres vessants del seu pensament. Només un estudi exhaustiu i en clau evolutiva dels sermons predicats els darrers anys permetrà de respondre amb rigor a aquesta pregunta.

\section{BIBLIOGRAFIA CITADA}

Alemany, Rafael (1995), Prosistes i intel-lectuals del segle XIV: sant Vicent Ferrer, dins Idem, Guia bibliogràfica de la literatura catalana medieval, Alacant, Universitat d'Alacant, pp. 97-105.

Beuchot, Mauricio (1995), Pensamiento filosófico de san Vicente Ferrer, València, Ajuntament de València.

Bianchi, Luca (1998), "Cum linea subducta damnavit": A proposito di Tommaso d'Aquino e Gioacchino da Fiore, "Florensia" 12, pp. 151-156.

Carbonero y Sol, León (1873), Sermones de san Vicente Ferrer sobre el Anticristo y el fin del mundo, "La Cruz" 1, pp. 145-154.

Cátedra García, Pedro María (1994), Sermón, sociedad y literatura en la Edad Media. San Vicente Ferrer en Castilla (1411-1412). Estudio bibliográfico, literario y edición de los textos inéditos, Salamanca, Junta de Castilla y León, Consejería de Cultura y Turismo.

Dabrowski, Wieslaw (2011), L'Anticristo secondo il commento di san Tommaso d'Aquino al "Corpus Paulinum", "Angelicum" 88, pp. 611-680.

Delcorno, Carlo (2006), Da Vicent Ferrer a Bernardino da Siena. Il rinnovamento della predicazione alla fine del Medioevo, dins Hodel, PaulBernard; Morenzoni, Franco (eds.), "Mirificus praedicator". À l'occasion du sixième centenaire du passage de saint Vincent Ferrier en pays romand. Actes du colloque d'Estavayer-le-Lac, 7-9 octobre 2004, Roma, Istituto Storico Domenicano, pp. 7-38 (Dissertationes Historicae; 32).

\footnotetext{
${ }^{50}$ L'elecció de Martí V va implicar de fet una certa temperància general en les expectatives apocalíptiques. $C f$. McGinn 1994 [trad. 1997], p. 200. Fuster 2004, p. 224, ha fet notar que a partir de l'any 1417 Vicent Ferrer "vuelve ahora a la serenidad de su primera época". $C f$. Gorce 1923 , p. 66. Els anys 1415-1416 són realment decisius per a mestre Vicent Ferrer. Efectivament, l'any 1415 es produeix la ruptura definitiva entre Ferrer i Benet XIII. Cf. McGinn 1998, p. 254; Perarnau 1998, p. 649. Vicent Ferrer reconeix en el de Constança un veritable concili, en el sentit més propi de la paraula i amb tota la càrrega teològica del terme.
} 
Delcorno, Carlo (2009), “Quasi quidam cantus”. Studi sulla predicazione medievale, Florència, Leo S. Olschki.

Dufeil, Michel-Marie (1972), Guillaume de Saint-Amour et la polémique universitaire parisienne 1250-1259, París, Éditions A. et J. Picard.

Elizande, Guillermo J. (2004), Santo Tomás de Aquino y Joaquín de Fiore, dins Petit Sullá, José María; Romero Baró, José María (eds.), Actas del congreso La Síntesis de Santo Tomás de Aquino (Barcelona, 1214 de septiembre de 2002), Barcelona, Publicacions i Edicions de la Universitat de Barcelona, vol. I, pp. 363-377.

Esponera Cerdán, Alfonso (2007), El oficio de predicar: los postulados teológicos de los sermones de san Vicente Ferrer, Salamanca, Editorial San Esteban.

Fages, Pierre-Henri Dominique (1903), Historia de san Vicente Ferrer, trad. Antonio Polo de Bernabé, vol. I, València, A. García editor.

Fages, Pierre-Henri Dominique (1905), Notes et documents de l'histoire de Saint Vincent Ferrier, Lovaina, Uystpruyst - París, Picart \& fils.

Ferrer, Vicent, Tractatus de suppositionibus, edició crítica, amb introducció de John A. Trentman, Stuttgart, Bad Cannstatt - Frommann, Holzboog, 1977.

Ferrer, Vicent, Quaestio de unitate universalis. מאמר נכבר בכולל (Ma'amar nikhbad ba-kolel). Text llatí i versió hebrea medieval amb traduccions catalana i anglesa. Edició a cura d'Alexander Fidora i Mauro Zonta, en col·laboració amb Josep Batalla i Robert D. Hughes, Santa Coloma de Queralt, Obrador Edèndum, 2010.

Fiorentino, Fernando (2007), L'Anticristo in S. Tommaso: a proposito delle radici cristiane dell'Europa, "Sapienza. Rivista internazionale di filosofia e di teologia" 60, pp. 241-252.

Forcada, Vicente; Garganta, José M. (1956), Biografía y escritos de san Vicente Ferrer, Madrid, Editorial Católica, pp. XXVI-XXXI (Biblioteca de Autores Cristianos; 153).

Fuster Perelló, Sebastián (2004), "Timete Deum”. El Anticristo y el final de la historia según san Vicente Ferrer, València, Ajuntament de València.

Gallego Salvadores, Juan José (1974), Santo Tomás y los dominicos en la tradición teológica de Valencia durante los siglos XIII, XIV y XV, "Escritos del Vedat" 4, pp. 481-569.

García Cuadrado, José Ángel (1994), Hacia una semántica realista: la filosofía del lenguaje de San Vicente Ferrer, Pamplona, EUNSA.

Garganta, Josep Maria de (1908), San Vicente Ferrer, predicador de penitencia y de reforma, dins Agiografia nell'Occidente cristiano. Secoli XIII-XV (Roma, 1-2 marzo 1979), Roma, Accademia Nazionale dei Lincei, pp. 128-165. 
Geltner, Guy (2012), The Making of Medieval Antifraternalism. Polemic, Violence, Deviance, \& Remembrance, Oxford, University Press.

Gorce, Matthieu-Maxime (1923), Saint Vincent Ferrier (1350-1419), París, Plon-Nourrit.

Gregory, Tullio (1962), Escatologia e aristotelismo nella scolastica medievale, dins L'attesa dell'età nuova nella spiritualità della fine del Medioevo (16-19 ottobre 1960), Todi, Accademia Tudertina, pp. 262-282 (Convegni del Centro di Studi sulla Spiritualità Medievale; 3).

Gregory, Tullio (1965), Sull'escatologia di Bonaventura e Tommaso d'Aquino, "Studi medievali" 6, pp. 79-94.

Hodel, Paul-Bernard (2005), La lettre de saint Vincent Ferrier à Benoît XIII, "Escritos del Vedat" 25, pp. 77-87.

Lamb, Matthew L. (2007), Wisdom Eschatology in Augustine and Aquinas, dins Dauphinais, Michael A.; David, Barry A.; Levering, Matthew (eds.), Aquinas the Augustinian, Washington, The Catholic University of America Press, pp. 258-275.

Lambertini, Roberto (2002), Ende oder Vollendung. Interpretazioni escatologiche del conflitto tra Secolari e Mendicanti alla metà del XIII secolo, "Miscellanea mediaevalia" 29, pp. 250-261.

Madalena, Tomás (1719), Crisis thomistica et novissima litteris emendatio "Summa Theologiae" Angelici Doctoris S. Thomae Aquinatis addiicienda, Saragossa, Apud heredes E. Roman.

McGinn, Bernard (1994), Antichrist. Two Thousand Years of the Human Fascination with Evil, San Francisco, Harpers Collins. N'hi ha traducció castellana: McGinn, Bernard (1997), El Anticristo. Dos milenios de fascinación humana por el mal, trad. Ramón A. Díez Aragón, María Carmen Blanco Moreno, Barcelona, Paidós Ibérica.

McGinn, Bernard (1998), Visions of the End. Apocalyptic Traditions in the Middle Ages. With a New Preface and Expanded Bibliography, Nova York, Columbia University Press, pp. 253-258.

Mensa i Valls, Jaume (2014), Arnau de Vilanova adversario de Tomás de Aquino: la polémica sobre la conveniencia de conocer los tiempos finales, "Archives d'histoire doctrinale et littéraire du Moyen Âge" 81, pp. 99-138.

Morenzoni, Franco (2004), La prédication de Vincent Ferrier à Montpellier en décembre 1408, "Archivum Fratrum Praedicatorum" 74, pp. 225-271.

Moya Cañas, Patricia (2000), Fin del mundo, según Tomás de Aquino, “Teología y vida" 41/1, pp. 52-58.

Perarnau i Espelt, Josep (1998), El punt de ruptura entre Benet XIII $i$ sant Vicent Ferrer, "Analecta sacra Tarraconensia" 71, pp. 625-659. 
Perarnau i Espelt, Josep (1999), Aportació a un inventari de sermons de sant Vicent Ferrer: temes bíblics, títols i divisions esquemàtiques, "Arxiu de textos catalans antics" 18, pp. 479-804.

Perarnau i Espelt, Josep (2007), recensió del llibre Fuster 2004 en "Arxiu de textos catalans antics" 26, pp. 816-820.

Robles, Adolfo (1998), Bibliografia, dins Ferrer, Vicent, Tractat de la vida espiritual. Sermons, Barcelona, Proa, pp. 54-56.

Rusconi, Roberto (1979), L'attesa della fine. Crisi della società, profezia et Apocalisse in Italia al tempo del grande scisma d'Occidente (13781417), Roma, Istituto Storico Italiano per il Medio Evo, pp. 219-233 (Studi Storici; 115-118).

Thomas de Aquino (1858), Commentum in quartum librum Sententiarum magistri Petri Lombardi, dins Opera omnia, vol. VII-2, Parma, Typis Petri Fiaccadori.

Thomas de Aquino (1949), Quaestiones disputatae, vol. II, De potentia, ed. Pauli M. Pession, Torí - Roma, Marietti, pp. 145-147.

Thomas de Aquino (1970a), Contra impugnantes Dei cultum et religionem, dins Thomas de Aquino, Opera omnia iussu Leonis XIII P.M. edita, vol. XLI/A, Roma, Ad Sanctae Sabinae.

Thomas de Aquino (1970b), Quaestiones disputatae de veritate, II-I (QQ 8-12), dins Idem, Opera omnia iussu Leonis XIII P.M. edita, Roma, Ad Sanctae Sabinae, vol. XXII, pp. 257-260, 393-394.

Velde, Rudi A. te (2002), Christian Eschatology and the End of Time according to Thomas Aquinas ("Summa contra gentiles" IV, c. 97), dins Aertsen, Jan A.; Pickavé, Martin (eds.), Ende und Vollendung. Eschatologische Perspektiven im Mittelalter, Berlín, Walter de Gruyter, pp. 595-604 (Miscellanea mediaevalia; 29).

Fecha de recepción del artículo: marzo 2014

Fecha de aceptación y versión final: febrero 2015 